\title{
DOCÊNCIA INICIAL EM EDUCAÇÃO DE JOVENS E ADULTOS E A POTÊNCIA DA NARRATIVA
}

\section{COMO DISPOSITIVO DE FORMAÇÃO}

\author{
SOUZA MARIA, Liliane Sant'Anna de $^{1^{*}}$; FONTOURA, Helena Amaral da ${ }^{2^{* *}}$ \\ ${ }^{1}$ Secretaria Estadual de Educação do Rio de Janeiro \\ ${ }^{2}$ Universidade do Estado do Rio de Janeiro \\ professoralilianesouza@gmail.com* \\ helenafontoura@gmail.com**
}

\section{RESUMO}

Objetiva-se refletir sobre as experiências de futuros professores em Educação de Jovens e Adultos (EJA). Utilizou-se o aporte (auto)biográfico pelo viés da pesquisa-formação, envolvendo os cotidianos da sala de aula e as narrativas dos estágios. As participantes da pesquisa narraram as experiências no caderno Bordado Formativo em EJA. Dialogou-se acerca da formação do educador da EJA, da trajetória social e pessoal dos sujeitos da pesquisa

e das especificidades da formação para a EJA. Os autores que serviram de aporte referencial foram Josso, Souza e Fontoura. A metodologia (auto)biográfica contribuiu para a formação identitária docente em EJA das alunas e das pesquisadoras, fortaleceu as aulas e estágios em EJA e potencializou a escrita como processo autorreflexivo e conhecimento das individualidades e coletividades no percurso de formação.

PALAVRAS-CHAVE: Curso normal. Educação de Jovens e Adultos. Pesquisa-formação. Narrativas da experiência.

\section{INITIAL TEACHING IN ADULT AND YOUTH EDUCATION AND THE POWER}

\section{OF NARRATIVES AS A TRAINING DEVICE}

\section{ABSTRACT}

The objective was to reflect on the experiences with future teachers in adult and youth education (EJA). We use (auto)biography by the bias of the research - training, involving day-to-day classroom and the narratives of the practicums. The research participants reported experiences in a notebook called Formation Embroidery in $E J A$. Data was analyzed in the light of thematization. Five students participated in the research, talking about the formation of the EJA educator, social and personal trajectory of the subjects of this research, and the specifications of training for Adult and Youth Education. Josso, Souza and Fontoura are the authors who contributed with our dialogues. The (auto)biographical methodology contributed to the students and researchers' teacher identity formation in EJA. It has strengthened the classes and internships in EJA and raped up the writing as self-reflective process and knowledge of individuals and collectivities in the training course. KEYWORDS: Normal course. Adult and Youth Education. Research-training. Experience narratives.

\section{DOCENCIA INICIAL EN EDUCACIÓN DE JÓVENES Y ADULTOS Y EL PODER}

\section{DE LA NARRATIVA COMO UN DISPOSITIVO DE ENTRENAMIENTO}

\section{RESUMEN}

El objetivo fue reflexionar sobre las experiencias de futuros docentes en Educación de Jóvenes y Adultos (EJA). Utilizamos la (auto)biografía por el sesgo de la investigación-formación, implicando el aula del día a día y las descripciones de las etapas. Las cinco participantes de la investigación narraron sus experiencias en el cuaderno Bordado Formativo en EJA. Se dialogó sobre la formación del educador de EJA, la trayectoria personal y social de los sujetos de la investigación y los detalles de la formación para la EJA. Josso, Souza y Fontoura sirvieron como aportes teóricos. La metodología (auto)biográfica contribuyó a la formación de la identidad del profesor de EJA y las investigadoras han fortalecido las clases y prácticas en EJA y han aumentado la escritura como proceso autoreflexivo y de conocimiento de los individuos y colectividades en el curso de capacitación.

PALABRAS CLAVE: Curso normal. Educación de Jóvenes y Adultos. Formación en investigación. Relatos de experiencia.

Educação \& Formação, Fortaleza, v. 3, n. 8, p. 118-137, maio/ago. 2018

DOI: http://dx.doi.org/

http://seer.uece.br/redufor 


\section{O FIO DA MEADA}

Como um tecido cobrindo, de cor em cor enfeitado, vamos nesse artigo, riscando o bordado tecido junto com os pares ${ }^{1}$. Assim, convidamos você, leitor, a caminhar junto e tecer ponto a ponto a composição da arte de (re)bordar a formação docente. Os fios serão as narrativas educativas dos normalistas e da professora pesquisadora, inseridos no cotidiano de uma escola do curso normal localizada na Baixada Fluminense, Rio de Janeiro, onde foi realizada a pesquisa de Mestrado.

Estávamos a meditar sobre o que temos bordado e estudado ao longo dessas linhas que (re)traçamos através de nossa docência e paramos para refletir: como escrever sobre narrativas educativas e de formação sem antes olhar, mesmo que brevemente, para a história que estamos (re)bordando em nossa docência e que vem (re)constituindo as telas desse bordado?

Propomos a você, "Dar a ler...talvez [...] no movimento da invenção e renovação [...] do imprevisível, da leitura por vir [...] um instante de atenção e escuta [...] com a que se prepara o talvez e na qual, talvez, se anuncia a sua vinda" (LARROSA, 2004, p. 16-29) e acompanhar conosco a tessitura breve da narrativa de parte de nossa vida profissional e de formação. Começamos a escrever sobre as histórias reais que foram arrancadas do silêncio e nos levaram a olhar para dentro de nós em contato com fotos, memórias, leituras, diálogos com colegas e nossos alunos, professores enfim, sujeitos do cotidiano que junto conosco entrelaçam nossa história de vida e formação e dão significado e cores a ela.

As marcas fixadas em nossa memória bordaram em nós identidade que ganha senso no rebrilho, e no alfinetar desses fios de histórias que se entrelaçam vamos ganhando o mundo e (re)construindo sentido por onde passamos. Bordar histórias de vida e formação é o que pretendemos com este artigo. Pesquisamos a formação de professores em Educação de Jovens e Adultos dentro do espaço escolar e, com o resultado desta investigação sobre a formação em EJA, hoje em forma de artigo, esperamos que os fios abertos para novas urdiduras reflexivas possam ajudar nos diferentes espaços que a EJA ocupa na atualidade e seus sujeitos, incluindo nós, as tecelãs como parte deste processo.

1 Entendemos ser importante resguardar a especificidade que faz parte da construção teórico-metodológica da pesquisa (auto)biográfica. Dentre as diferentes especificidades deste campo de pesquisa, está a presença da dimensão poética e estética. Para maior aprofundamento, ver Ferrarotti (2014).

Educação \& Formação, Fortaleza, v. 3, n. 8, p. 118-137, maio/ago. 2018

DOI: http://dx.doi.org/

http://seer.uece.br/redufor 
Os contos poéticos do moçambicano Mia Couto muito nos auxiliam na composição e reflexão deste bordado formativo quando o autor afirma que a tecelã em cantos e recantos deixa a sua marca, o engenho da sua seda e diz que o que faz é arte. Pensamos ser a arte de educar e coser relações com os sujeitos que convivemos cotidianamente em nosso urdir em educação e atualmente na Educação de Jovens e Adultos.

Com isso, entrelaçamos parte do poema com o uso da metáfora do bordado. 0 propósito é refletirmos sobre as experiências docentes que desenvolvemos com nossos alunos e alunas, bem como também coser nossa própria história formativa.

Assim, explicitamos o quanto foi difícil desenvolvermos os primeiros pontos deste artesanato, em nossa trajetória de formação profissional. Este exercício de escrita/reescrita tocou-nos profundamente e projetou nosso olhar para os detalhes do bordado experiencial (JOSSO, 2010b) “[...] e é com dificuldade que normalmente se operacionaliza o exercício da reflexão sobre si mesmo no contexto de formação" (PASSEGGI; CUNHA, 2013, p. 45). Segundo Josso (2010b, p. 60), esta experiência “[...] apela para emoções, sentimentos, sentidos ou valores", trazendo a consciência quanto às vivências e recordações que por algum motivo ficaram escondidas em nossa memória e, atualmente têm alimentado autoconfiança e, por vezes, revelando as dúvidas e incertezas da vida. As nossas experiências com a escola, seus encantos e desafios, os quais formam em nós, eu pessoal e profissional (NÓVOA, 1992) nos apaixonam e ocasionam mudanças porque têm ocorrido dentro de um processo de coinvestimento entre as professoras pesquisadoras em processo de formação junto com os alunos. Assim, convidamos você leitor, a entremear conosco fios reflexivos sobre a docência inicial em EJA neste artigo.

\section{TRAMAS E ENTRELACES: URDIDURAS REFLEXIVAS}

A educação de pessoas jovens, adultas e idosas, possui particularidades e especificidades importantes e, para que se possa avançar com a educação para este público e buscar justa equidade e reparação da dívida inscrita por décadas aos sujeitos da Educação de Jovens e Adultos (EJA), é urgente entremearmos e repensarmos a maneira como vem se constituindo a formação docente e suas práticas em diferentes espaços, isto porque os

Educação \& Formação, Fortaleza, v. 3, n. 8, p. 118-137, maio/ago. 2018

DOI: http://dx.doi.org/

http://seer.uece.br/redufor 
professores, como sujeitos da EJA, possuem um papel estratégico neste momento de transição em que vive a EJA.

Na trilha cujas linhas fazem parte do bordar a formação docente, Soares (2011, 2014), após pesquisas realizadas sobre a formação inicial de professores para a EJA, destaca que ainda não temos claro quais são as especificidades necessárias que norteiam a formação docente, carecendo de pesquisas que desvelem tal premissa e revelando que a Educação de Jovens e Adultos vive em um momento de mudanças nas políticas públicas, cujas especificidades devem ser levadas em consideração em tempos e espaços específicos e no momento da formação em si, pois "estamos em um período de transição, convivendo com antigas práticas como a do ensino supletivo, [...] como um ponto de nó, e uma nova concepção de educação expressa pelo direito e por uma educação de qualidade" (SOARES, 2002, p. 8) buscando pontos possíveis de bordar e re(bordar).

Para o referido autor, muitos docentes que atuam na EJA não possuem formação adequada para atender às diversidades dos sujeitos tais como privados ou não de liberdade, quilombolas, indígenas, afrodescendentes, portadores de necessidades especiais, aos sujeitos do campo e de diferentes orientações sexuais, credo religioso, ocupação profissional, situação social, enfim, características de um ponto aberto, cujos sujeitos com especificidades e realidades diversas, por décadas tentam juntar um fio a outro a várias mãos, com experiências de vida e de formação bem diferentes de outras faixas etárias como a infantil, por exemplo, e respeitar essa diversidade e diferenças na EJA se faz necessário porque:

\footnotetext{
Assim como a diversidade, os processos e a luta pela inclusão na educação básica representam mais do que a incorporação total ou parcial dos chamados 'diferentes' aos espaços e tempos escolares a eles negados historicamente. Eles implicam posicionamento político, reorganização do trabalho na escola, do tempo escolar e da formação de professores [...], novas alternativas para a condição docente e uma postura democrática diante do diverso. (BRASIL, 2008).
}

É necessário, neste período de transição pelo qual passa a EJA, que ocorra uma reorganização e um novo posicionamento pedagógico do professor nos diferentes espaços e tempos da EJA, com formação docente sólida que atenda à diversidade de sujeitos e que possa verdadeiramente incluir todos os alunos/as no processo de ensino aprendizagem mútuos, procurando escapar das amarras do nó já dado, do nó cego e fechado.

Educação \& Formação, Fortaleza, v. 3, n. 8, p. 118-137, maio/ago. 2018

DOI: http://dx.doi.org/

http://seer.uece.br/redufor 
Assim, uma proposta que tende a dar essa abertura e tecer um reposicionamento na tela da arte em EJA do educador (seja em formação inicial ou continuada) frente a esta realidade de sujeitos, é a perspectiva da metodologia (auto)biográfica. Essa proposta epistemológica e metodológica de formação dos sujeitos, leva em conta as histórias de vida, além de possibilitar o trabalho com o dispositivo da pesquisa formação de adultos e de professores (JOSSO, 2010b).

O campo da abordagem (auto)biográfica em educação surgiu no seio da crise, de um bordado desfigurado das investigações sociológicas rigidamente estruturadas do ponto de vista metodológico formal e de sua insuficiência em dar conta dos problemas e das subjetividades humanas. No bojo dessa crise estão as questões humanas, a separação do sujeito e objeto e a defesa de uma neutralidade. Eis que surge, então, o movimento das pesquisas (auto)biográficas buscando uma renovação metodológica, como aponta Bragança (2008).

O caminho da perspectiva (auto)biográfica possui diferentes dimensões na compreensão dos sujeitos e suas experiências formativas, surgindo nas décadas de 80 e 90 através de seus precursores, Pineau (1983), Dominicé (1990) e Josso (1991), quando estes dialogam sobre as histórias de vida como caminho metodológico para a autoformação, ganhando força ao colocar os autores das narrativas como protagonistas do conhecimento que eles mesmos constroem. Bragança (2008) afirma que a biografia educativa e a autoformação como recurso metodológico, fortaleceram o desenvolvimento da pesquisa (auto)biográfica influenciando fortemente o campo da formação de professores.

Essa mesma autora destaca que essa perspectiva teórico-metodológica apresenta uma “[...] polifonia de marcas em pesquisas e práticas articuladas às histórias de vida e formação [...] a presença do diálogo interdisciplinar e abertura à literatura e à arte" (BRAGANÇA, 2008, p. 68) e diferentes campos do conhecimento como História, Antropologia, Psicologia, Filosofia e Biologia como fios coloridos em diferentes novelos e de várias formas. A autora continua afirmando que essa polifonia de aporte teórico-metodológico enriquece as possibilidades de análise e interpretação das histórias de vida, na tentativa de se desvencilhar das perspectivas disciplinares rígidas que desconsideram as formas de vida, compreensão e aprendizagem dos sujeitos que narram, convertendo a rota para uma nova epistemologia, dando visibilidade às experiências, tão importantes para o campo da EJA, porque possibilita atender às especificidades dos sujeitos.

Educação \& Formação, Fortaleza, v. 3, n. 8, p. 118-137, maio/ago. 2018

DOI: http://dx.doi.org/

http://seer.uece.br/redufor 
Em se tratando no campo da formação docente, Nóvoa (1992), na tentativa de sistematizar essa grande diversidade de polifonia no aporte teórico-metodológico da metodologia (auto)biográfica, os dividiu em objetivos e dimensões destacando-os quanto aos objetivos: trabalhos essencialmente teóricos com relação à investigação, essencialmente práticos com relação à formação e essencialmente emancipatórios com relação à investigação-formação. Sobre as dimensões, envolve estudos sobre a pessoa, as práticas e a profissão.

O novo paradigma de conhecimento centrado nos percursos de vida do sujeito aprendente tem como um dos fios tecidos dos aportes epistêmico-metodológicos a pesquisa formação atrelada às histórias de vida, um diferencial para as pesquisas em diversos campos do conhecimento, sobretudo no campo da educação vinculado à formação docente ligada ao local de trabalho e/ou formação (JOSSO, 2010b). Esse bordado gira em torno de dois eixos fundamentais: o projeto teórico cuja compreensão está intimamente ligada à biografia da formação em torno da autoformação, vinculado à perspectiva da pesquisa-formação; e outro eixo, a perspectiva biográfica em torno de projetos - aqui destacamos, dentre muitos elencados pela autora, o projeto de formação (JOSSO, 2010b). Experiências formativas a partir das narrativas acontecem por estas possuírem caráter heterogêneo e, com isso, passam a ganhar visibilidade ao serem consideradas a partir das experiências dos sujeitos em tessitura com os seus processos formativos. Isso significa dizer que as narrativas devem ser analisadas dentro de um contexto e de um projeto, neste caso específico: a formação docente entrelaçada com os sujeitos com os quais os professores atuam em seu cotidiano.

Assim, convidamos para dar cores e tons específicos nesta arte, a perspectiva epistemológica e metodológica da abordagem experiencial, pelo viés da pesquisa-formação preconizada por Josso (2010b, p. 141), em que cada etapa “[...] é uma experiência a ser elaborada para quem nela estiver [...] possa participar de uma reflexão teórica sobre a formação e os processos por meio dos quais ela se dá a acontecer". É uma abordagem metodológica com o foco nas dinâmicas dos sujeitos no mundo, com suas aprendizagens e valores dentro de diferentes contextos que são próprios de quem nele está, possibilitando a tela da arte aberta, colorida e vistosa em sua urdidura. Esta perspectiva metodológica é pertinente na educação de adultos destacando o lugar e o sentido da formação (JOSSO, 2010a) inserida na biografia educativa que envolve as histórias de vida e de formação. Portanto, é recomendável para se 
compreender as "especificidades" (SOARES, 2008) da formação docente em EJA, no intuito de tecer outro artesanato.

Esse caminho aponta para dois objetivos: mudança no processo e no posicionamento do professor através do viés da pesquisa-formação, de acordo com a forma e com o papel assumido pelo professor diante das etapas e projetos de conhecimentos dessa metodologia; direciona para uma nova forma de reflexão sobre a formação e a autoformação. Assim, essa abordagem metodológica encaminha para análises subjetivas e intersubjetivas dos sujeitos ao produzirem saberes, sentidos ao narrarem suas histórias, potencializando um trabalho formativo e autoformativo em educação de adultos e favorecendo a organização de experiências vividas, auxiliando e melhorando substancialmente o trabalho pedagógico desenvolvido nos espaços educativos com os alunos, como assinala Bragança (2008, p. 78-79):

[...] a narrativa é como ação rebelde [...] afirma-se enquanto um caminho de aprendizagem coletiva, incorporando vozes silenciadas pela política educacional e de formação docente, produzindo uma contracultura em posição a oficial [...] na abertura de um diálogo que faz e se refaz na luta cotidiana da vida e da profissão, [...]. E, assim, no plural vai se fazendo a formação, na intensa construção da vida.

Com isso, temos a possibilidade de, a partir das narrativas (auto)biográficas, possibilitar aberturas às práticas docentes, tornando-as mais próximas das realidades dos sujeitos da EJA, além de reposicionar o educador nos processos de ensinar e aprender junto com os outros, elemento chave neste momento de transição política em que passa a Educação de Jovens e Adultos, entrelaçando experiências e (re)tecendo novas telas com pontos sempre abertos na arte. Outro ponto importante é a reorganização nas dinâmicas das aulas porque a alteridade e a diversidade de realidades passam a ser o centro do processo, o fio condutor da tessitura do processo pedagógico. Um projeto em que o professor esteja pautado nesta perspectiva trará mais sentido para os alunos porque as ações são planejadas e executadas a partir das experiências de vida (LARROSA, 2002) e não o seu oposto, possibilitando que os conhecimentos das diferentes áreas do saber passem a ter uma nova rota a seguir, pois são provenientes das vivências e experiências de onde serão extraídos os conteúdos, favorecendo um conhecimento mais contextualizado e com sentido para quem aprende, a saber os tecelões sujeitos da EJA. Cria-se com esse reposicionamento do professor da EJA, a possibilidade de inclusão dos diferentes sujeitos no processo de aprendizagem, isso porque é coletiva (respeitando as especificidades 
individuais) em substituição de um fazer docente para alunos, pelo fazer juntos, com os educandos, trazendo mais sentido e prazer ao cotidiano de alunos e professores, com a viscosidade do ponto haste.

Neste entrelace teórico-metodológico, narramos a experiência da pesquisa que desenvolvemos junto a cinco professorandas em formação inicial na EJA. A tessitura foi preenchida por tramas e entrelaces das narrativas autobiográficas dos alunos do curso normal, atravessados pelos fios de diversos dispositivos potencializadores de reflexão, e, para este artigo, ficaremos com uma parte da pesquisa que envolveu as experiências iniciais de docência em EJA das professorandas - reflexões sobre os estágios partindo das experiências narradas por escrito no caderno de campo denominado: Caderno do Bordado Formativo em EJA - que desenharam uma parte das telas da arte.

$\mathrm{Na}$ urdidura de um bordado todos conseguem ver as missangas, os pontos e os efeitos da beleza que o artesanato forma, mas os fios que conduzem os pontos e desenhos que sustentam as missangas não são vistos, entretanto, apoiam a graciosidade e riqueza de uma obra artesanal. Assim são as narrativas escritas nos diários de campo denominado Bordado Formativo em EJA - em momentos das aulas na disciplina Conhecimentos Didáticos e Pedagógicos em EJA (CDPEJA), que ocorreu em três turmas do último ano do curso normal - missangas graciosas, coloridas, sustentadas pelos fios da pesquisa formação. Foram doze encontros, de março a outubro de 2015, distribuídos entre três bimestres, envolvendo as temáticas dentro do planejamento da disciplina para além do currículo mínimo - e seu ponto de nó que amarra e limita o artesanato -, instituído pela Secretaria Estadual de Educação do Estado do Rio de Janeiro (SEEDUC/RJ). Seguimos um roteiro com diferentes temáticas e fios de várias cores e espessuras e, neste artigo destacamos o que nos ajudará a refletir sobre a experiência: 1. Fiando as aulas de Conhecimentos Didáticos e Pedagógicos em EJA onde as alunas narraram a contribuição da disciplina para sua formação envolvendo a perspectiva da identidade e as professorandas narraram também o impacto da perspectiva (auto)biográfica como eixo importante dessa formação; 2. Estágio na EJA revelando as experiências e aprendizagens oriundas desse contexto.

Assim, as aulas foram organizadas no intuito de as alunas narrarem suas histórias de formação e socializarem suas vivências e aprendizagens de formação pessoal e docente; o que foi aprendido a partir da reflexão sobre o que se viveu e se observou sobre a prática tecida dos 
sujeitos com os quais conviveram; as conversas, leituras e escritas no caderno do Bordado Formativo em EJA, além do que as alunas conseguiram documentar sobre o que viram, observaram e fizeram - suas inquietações, dificuldades e conquistas.

As cinco professorandas que preencheram a trama, narram parte de suas histórias e voluntariamente aceitaram o convite de participar dessa pesquisa, autorizaram terem seus nomes reais escrito nas narrativas. Muitas narraram terem aceitado participar pelo encantamento com a EJA, a partir de sua entrada no estágio de observação e prática docente. Outras, apesar de todo contato com o estágio em EJA, quiseram participar da pesquisa mesmo não desejando atuar nesta modalidade.

Para fiar as narrativas e interpretá-las, apoiamo-nos em Fontoura (2011b) e em sua proposta de tematização, que prevê a transcrição das narrativas, leitura atenta para conhecimento do material, demarcar o que é relevante com delimitação do corpus de análise, levantamento de temas, definição de unidades de contexto, interpretação à luz de referenciais teóricos e composição de um novo texto, no intuito de apoiar a base de análise no tear.

A intenção foi partir das experiências de formação de professores para desvelar a contribuição desse processo formativo na adequação e preparação para profissionais trabalharem com jovens e adultos, bem como compreenderem problemas educativos e sociais que possam ocorrer no cotidiano escolar. Assim, pretendemos com este bordar em grupo, propiciar a junção do pensar e do fazer, provocando troca de experiências para além do verbal e fortalecer nossa inserção no mundo no qual bordamos livremente os espaços formativos através das imagens e experiências vividas no cotidiano da EJA, com fios e cores que foram se descortinando à medida que a trama foi se compondo.

Nas análises das narrativas das tecelãs foram marcantes às aulas da EJA como um ponto importante para o fortalecimento identitário nesta modalidade:

Quando a professora comentou em sala de aula sobre a EJA, eu fiz uma reflexão dentro de mim, pois eu não sabia da existência dessa modalidade. (STÉFANE).

Quando iniciei aqui no curso normal, meu objetivo era apenas trabalhar com Educação Infantil, mas não tenho mais esse objetivo. Daqui para frente é ser professor da EJA. Tive uma visão diferenciada de enxergar essa modalidade. (GISELE).

As aulas da EJA me fizeram sentir mais confiante, pois não acreditava em meu potencial. (SARA).

Educação \& Formação, Fortaleza, v. 3, n. 8, p. 118-137, maio/ago. 2018

DOI: http://dx.doi.org/

http://seer.uece.br/redufor 
Essas narrativas nos revelam os registros dos desafios de conhecimento a partir da consciência que as participantes obtiveram no caminho formativo teórico refletido na prática. À medida que os itinerários de experiências foram se construindo, as opções e rejeições foram se colocando em evidência, tecendo com isso o início da identidade para EJA, porque, "[...] para que uma experiência seja considerada formadora, é necessário falarmos do ângulo da aprendizagem [...]" (JOSSO, 2010a, p. 34), profundamente ligada ao contexto social no qual estão inseridas, a saber, a escola. Para Bragança (2012), essas experiências possibilitam aos sujeitos em movimento formativo se relacionarem com o saber e oportunizarem reelaborações de conhecimentos reconstruindo práticas de formação em contexto pessoal e coletivo, favorecendo a reflexão das próprias experiências, como evidenciaram as narrativas das professorandas.

Assim, as relações que vão se formando cotidianamente entre os pares com os quais convivem os sujeitos, expressas nas narrativas como as aulas da EJA, contribuíram para o início da constituição identitária docente e na maneira como cada professoranda se olhava. Isto porque o período da formação inicial denominado de "pré-profissional" revela "[...] o ponto de partida e o momento das primeiras incursões [...] das descobertas dos interesses e motivações pessoais em relação aos campos profissionais" (FIDALGO; MACHADO, 2000, p. 125).

Essas experiências de conhecimento oriundo das aulas de EJA marcaram as aprendizagens sobre a importância da EJA porque é uma forma de ter uma relação em que se experimente, algo como uma travessia, e que possui íntima relação com o sujeito da experiência que se "[...] expõe atravessando um espaço indeterminado e perigoso, pondo-se nele à prova e buscando-se nele sua oportunidade, sua ocasião" (LARROSA, 2002, p. 25).

Soares (2006) destaca ser importante que se tenha na formação profissional o foco nas especificidades dos sujeitos da EJA revelando a importância de se trabalhar desde a formação inicial as particularidades necessárias para se trabalhar com os alunos. Portanto, barreiras devem ser derrubadas, tais como: queda do preconceito e estigma com relação aos alunos da EJA, além de métodos e conteúdos próprios para se trabalhar especificamente com adultos. Um dos caminhos apontados pelo autor é o trabalho com as histórias pessoais dos alunos como "relevante e diferenciador na prática profissional dos que atuam na EJA" (SOARES, 2006, p. 13), no intuito de juntar um fio a outro. Essa responsabilização e interesse com a formação docente a partir do professor formador, dentro da perspectiva da abordagem das biografias educativas, é 
peça importante nas políticas de formação e do conhecimento dos que desejam ser professores em busca de melhores tempos de estudo e preparação prévios que antecedem a prática das professorandas na luta pelo direito dos sujeitos da EJA.

Ainda na dimensão da perspectiva (auto)biográfica, as professorandas teceram, a partir de suas narrativas, a contribuição das aulas como eixo importante da formação e fortalecimento identitário com a EJA, solidificando a formação, oportunizando o conhecimento de si e do outro, a mudança de perspectiva e a reflexão. Por ser uma metodologia potente, pode se constituir espaço em que os alunos - futuros professores - sejam reconhecidos como sujeitos capazes de exercitar a reflexão sobre suas histórias e as de outros, sobre o cotidiano real das escolas e construir conhecimento ao longo de suas vivências, como narraram abaixo:

\begin{abstract}
As aulas da EJA foram reflexivas. Conhecemos uns aos outros, mudamos nossa maneira de pensar e agir a respeito um do outro. As aulas de EJA contribuíram para a minha formação docente, pois enriqueceram os meus conhecimentos. Conhecer mais sobre a EJA fez com que minha formação profissional fosse aprimorada. (STÉFANE).

Uma disciplina que nos leva realmente a refletir sobre nós mesmos e nossas atitudes perante algumas situações que vivenciamos em nossa vida. O mundo é feito de escolhas e eu escolhi ser professora da EJA. Tantas histórias, tantos momentos que nos levam a nos enxergar por dentro. (GISELE).
\end{abstract}

Nos fez entender o ponto de vista da outra pessoa. As aulas são significativas para minha formação como professora. (SARA).

Os espaços de formação estimularam uma perspectiva crítico-reflexiva em um movimento contínuo em aprender, desaprender e (re)aprender, como proposto pela pesquisa-formação (JOSSO, 2010a). Um conhecimento de si e das relações que teceram com o processo formativo na EJA porque colocou o sujeito e suas formas de compreender as suas experiências no centro do processo, por isso foram formadoras. Possibilitaram refletir sobre sua identidade para si e para outros, porque segundo as narrativas, inaugurou a abertura chamada de experiência fundadora, pois supôs novidade, transformação, mudança e interrogações sob as relações vividas, conforme afirma Josso (2010a), expressadas nas narrativas como "entender o ponto de vista da outra pessoa", "refletir sobre nós mesmos e nossas atitudes", "conhecemos uns aos outros mudamos nossa maneira de pensar e agir a respeito um do outro".

Trabalhar com a perspectiva (auto)biográfica nos processos formativos possibilitou às professorandas "[...] experiências com as quais o autor/ator aprendeu, mediante seu modo de 
operar escolhas, de se situar em seus vínculos e de definir seus interesses, nas valorizações e aspirações" (JOSSO, 2010b, p. 69), concebendo o trabalho com e sobre identidades para formação de professores em EJA. Os acontecimentos pessoais no processo formativo, valores e valorizações nortearam escolhas e foram dando contorno às singularidades e identidades dentro do percurso de formação nas biografias educativas. Fragmentos na busca de si e de sua projeção que, embora às vezes não se reconheça, agem e reagem diante das circunstâncias pelas quais vivenciaram de forma polissêmica, fortalecendo o trabalho biográfico dentro da formação e do conhecimento de si das alunas.

\section{O ENTRELACE TEMÁTICO DA DOCÊNCIA INCIAL EM EJA}

Neste entrelace temático, as narrativas nos revelaram as experiências tecidas nos estágios em EJA. Utilizamos o caderno do Bordado Formativo como propulsor da reflexão. Refletimos juntos sobre as práticas que vivenciaram: o perfil dos alunos da EJA e as aulas da EJA nos estágios.

Com relação às narrativas sobre os sujeitos da EJA, apareceu o subtema que denominamos da timidez aos encantos com os sujeitos da EJA, que marcou a experiência fundadora (JOSSO, 2010b) das alunas:

\footnotetext{
Como eu nunca tinha entrado em uma sala onde tinham muitos adultos estudando, fiquei muito tímida e num canto. Conforme foi passando o tempo, interagi mais com a turma. Levantei, ajudei, ensinei e ainda fiz amizades. (CINDY).

Cheguei na EJA com um pouco de medo da reação dos alunos, medo de não gostar. Fiquei na turma de 5o ano. O estágio de EJA foi uma experiência incrivel. No começo, tive muito medo, medo de não gostar, dos alunos não quererem aprender comigo, de não dar a explicação certa, de ensinar errado, de os alunos não aceitarem o jeito que eu explico, mas com o passar do tempo esse sentimento saiu todo de dentro de mim e foi se tornando em alegria, sentimento de missão cumprida. Foi uma experiência que vou levar para o resto da vida. (SARA).

Nossa! Como eu estava ansiosa para começar o estágio. Os alunos são tão amorosos comigo que a ansiedade e o nervosismo passaram na hora. Eu nunca imaginei que poderia ajudar alguém mais velho do que eu. Se caso surgir oportunidade para atuar nesta modalidade da EJA, atuarei com muito prazer. Através das aulas da EJA e da prática no estágio, me sinto muito mais preparada para minha formação docente e confiante. (THAYANNE).
}

Educação \& Formação, Fortaleza, v. 3, n. 8, p. 118-137, maio/ago. 2018

DOI: http://dx.doi.org/

http://seer.uece.br/redufor 
Notamos que, ao iniciarem os estágios na EJA, as alunas demonstraram timidez, medo, ansiedade e insegurança inicial na docência. Mas à medida que começaram a se aproximar e terem contato com os sujeitos, a identificação, admiração, experiência, preparo, ensino, receptividade, confiança, felicidade, identidade, auxílio, prazer, aprendizagem, alegria, dever cumprido, amorosidade foram dando lugar às experiências, segundo as narrativas. A ideia que os outros têm sobre elas e que elas têm de si, e como se percebem a partir dos outros é condição importante na tessitura da docência em EJA para reconhecer-se como profissional e como pessoa, em uma tomada de consciência sobre quem são os sujeitos da EJA. As professorandas carregavam uma imagem desfigurada da EJA como "marginalizados, excluídos, desiguais, inconscientes" (ARROYO, 2014, p. 40), dentro de uma concepção preconceituosa e superficial sobre os alunos da EJA e que, na verdade, houve uma troca, pois as alunas aprenderam muito mais do que ensinaram. As professorandas enfrentaram o medo e avançaram na prática de estágio docente. A origem social desses alunos da EJA é semelhante à das professorandas, facilitando a aproximação entre eles.

Atitudes de defesa como dispositivo de proteção em reação à insegurança gerada no primeiro contato com os sujeitos da EJA e, aos poucos, o sentimento de pertencimento foi surgindo, revelando o potencial das relações interpessoais e intrapessoais no exercício da docência. Essas experiências do campo da afetividade fortalecem a docência na EJA, contribuindo para solidificação dessa identidade profissional, evidenciadas nas narrativas a partir das expressões "sentimento de missão cumprida", "Se caso surgir oportunidade para atuar nesta modalidade da EJA, atuarei com muito prazer", "Através das aulas da EJA e da prática no estágio, me sinto muito mais preparada".

Esse sentimento de acolhimento e pertencimento no grupo, forte característica dos sujeitos da EJA nessa realidade formativa, foi um exercício de autonomia necessário para fortalecimento da docência das professorandas. Aprender a profissão docente exige um outro nas interações dialógicas (FREIRE, 1987) e nas suas próprias experiências, tornando-se significativa à medida que passamos a refletir sobre ela e transformando-a (FREIRE, 2000).

A afetividade é apresentada como uma alternativa de acolhimento entre as professorandas e os alunos da EJA, característica de uma educação humanizante defendida por Freire (1987). Essas relações sócio afetivas criam e ampliam os elos entre os sujeitos favorecendo 
o respeito mútuo no cotidiano, compondo com isso, um dos pilares da profissão docente para essa modalidade.

Para Marcelo Garcia (2010, p. 18), “[...] a motivação para ensinar e para continuar ensinando é intrínseca, fortemente ligada à satisfação por conseguir que os alunos aprendam, desenvolvam capacidades, evoluam e cresçam". Portanto, o vínculo afetivo com os sujeitos da EJA gera motivação para o desenvolvimento pedagógico do trabalho e, consequentemente, o sucesso na aprendizagem dos alunos como um dos pilares para as especificidades do trabalho com o público da EJA, como afirma Soares (2011, p. 307-308):

\begin{abstract}
A construção de uma proposta de trabalho que reconheça as especificidades do público da EJA perpassa por diversos aspectos: a diversidade de sujeitos educandos com características peculiares, [...] interesses desses sujeitos [...] iniciativas de formação inicial e continuada de educadores [...] às necessidades, [...] aos desejos e aos limites dos educandos.
\end{abstract}

Para o autor, somente será possível compreender as especificidades se estivermos junto às diversas realidades formativas, nos aproximando dos projetos educativos onde as formações ocorrem porque cada espaço e realidade de formação possui especificidade própria, única.

O segundo subtema tratou de abordar as aulas das professorandas onde realizaram seus estágios com forte presença do uso das histórias de vida nas aulas prática das alunas. É importante salientar que as professorandas, junto com o professor da turma em que fizeram o estágio, combinaram qual conteúdo abordar e, em sua maioria, as alunas escolheram trabalhar com as histórias de vida e, devido à alta demanda na procura de estágios por alunos do curso normal e Pedagogia, as alunas deram aula em duplas.

Hoje foi a minha aula prática junto com meu colega Wellerson. Trabalhamos história de vida como a professora fez conosco em sala de aula. Levamos uma caixa com um espelho dentro e eles tinham que dizer o que eles viam. (CINDY).

Levei a turma para a quadra e fiz um círculo com eles e distribui um pirulito para cada um. Através da Dinâmica do pirulito pretendi desenvolver o conceito de auxílio mútuo e a importância da reflexão sobre o próximo em nossa vida. (STÉFANE).

A nossa aula prática foi sobre história de vida. Os alunos tiveram que contar a sua história como quisessem. Comecei a aula falando sobre o que era a história de vida e logo após, com a permissão do professor da turma em que fiz o estágio, os alunos começaram a contar sua história. (THAYANNE).

Educação \& Formação, Fortaleza, v. 3, n. 8, p. 118-137, maio/ago. 2018

DOI: http://dx.doi.org/ 
A decisão dos alunos em abordar o uso das histórias de vida na perspectiva das biografias educativas em sua prática de estágio nos dá pistas da importância dessa metodologia no processo de formação inicial docente. As narrativas deixam rastros de que as aulas da CDPEJA marcaram fortemente a identidade das alunas na medida em que também decidiram adotar a proposta em sua prática desvendando modelos e princípios que estruturam discursos pedagógicos compondo o agir e o pensar das professoras em formação para além dos modelos de racionalidade técnica (SOUZA, 2008). O conteúdo que se ensina gera identidade porque "a forma como conhecemos uma determinada disciplina ou área curricular, inevitavelmente, afeta a forma como depois a ensinamos" (MARCELO GARCIA, 2010, p. 14). Conhecer o conteúdo que vai ensinar ajuda a determinar o que os professores vão lecionar e, com isso, os estágios desempenham papel importante na hora de interpretar as experiências de formação (MARCELO GARCIA, 2010). As experiências da prática na EJA nos deram pistas do "efeito que a dita experiência venha a ter em [...] aprendizagens posteriores" (MARCELO GARCIA, 2010, p. 16). Conhecer sobre o que vai ser ensinado poderá desenvolver uma prática mais eficaz porque é conhecendo o coletivo para quem se ensina que coletivamente vai se construindo o saber docente, constituindo sua identidade de professor(a).

A forma como tecemos a docência com as normalistas, a dinâmica das aulas, fizeram parte das escolhas individuais que não são aleatórias e possuir uma formação docente, com qualidade, preconiza "[...] uma formação de professores construída dentro da profissão, isto é, baseada numa combinação complexa de contributos científicos, pedagógicos e técnicos, mas que tem como âncora os próprios professores, sobretudo os professores mais experientes" (NÓVOA, 2009 , p. 9). Assim, os professores assumem sua prática a partir dos significados que eles mesmos dão como importantes.

\section{FIOS ABERTOS DAS CONSIDERAÇÕES FINAIS}

Fazer pesquisa com narrativas pode ser considerado fazer poesia, literatura, ser menos científico, não ter valor como pesquisa, nada mais longe de nossa opção. As produções dos eventos na área de (auto)biografia mostram a relevância dessa opção teórica e metodológica, que possibilita aos participantes entrarem em contato com suas experiências vividas, ressignificá-las e 
se construírem melhores pessoas e profissionais mais fortalecidos. A limitação desse tipo de estudo vem, muitas vezes, da incompreensão por alternativas de investigação que fortaleçam os que trabalham na área, de modo a terem práticas pedagógicas mais de acordo com seus anseios, suas experiências e seus saberes.

Assim, as narrativas demonstraram a importância desta pesquisa para a formação inicial docente em EJA na medida em que, juntos, tecemos nossa identidade pessoal e profissional através das experiências que possibilitaram conexões e pistas relevantes para esta modalidade de ensino. Nesse artesanato formativo em EJA, refletimos, tornamos visíveis os conhecimentos e experiências de formação, percepções de si, interesses, inquietações, dúvidas, e aberturas possíveis na trama para o futuro das professorandas e as professoras pesquisadoras, sem esquecer que, nesta diversidade que caracteriza a EJA, não só os alunos são sujeitos da Educação de Jovens e Adultos, mas também os professores - quer seja na formação inicial ou continuada em EJA. Por isso, terminamos este artigo com as reticências de quem tem a consciência do longo caminho a trilhar na perspectiva da educação por toda a vida entrelaçado ao pronome nós em diálogo.

A quantidade de histórias lindas de professorandas e professorandos que teceram sua trajetória de formação em EJA foi enorme. Não pudemos incluir as histórias inteiras para não embaraçar o novelo e nem perder o fio da meada. Limitamo-nos a fazer referência a estas cinco professorandas e aos sujeitos que, junto conosco, riscaram e teceram o bordado.

No âmbito das contribuições dessa pesquisa, as cores dadas aos fios que foram entremeados, a partir das reflexões teóricas e práticas, nos auxiliaram a pensar à docência, levando em consideração os aspectos psicológicos e sociais das professorandas e dos sujeitos que, juntos, trilharam suas experiências de vida e formação. Assim, essa formação de professores em nível médio levou em consideração aspectos concernentes à ação pedagógica no âmbito das reflexões e estudos de narrativas de si atrelada às teorias e práticas em EJA.

Dentro dessa realidade formativa, os estágios tramados às reflexões no âmbito das aulas da disciplina CDPEJA constituíram ricos momentos de formação porque as professorandas junto às professoras pesquisadoras e os sujeitos dos estágios em EJA puderam vivenciar experiências, conhecendo melhor as especificidades dessa realidade, corroborando para a reflexão sobre a área de atuação docente em EJA (SOARES, 2014). Nesse estágio, que não foi tarefa fácil, descortinamos a heterogeneidade e diversidade dos sujeitos da EJA trançados com a pessoa das 
professorandas e, notadamente, aproximações materiais de vida, de cultura, se assemelharam e acabaram encantando as estagiárias enquanto realidade histórico-social.

O trabalho desenvolvido aponta para a potencialidade da escrita (auto)biográfica em contexto de formação na perspectiva de Bragança (2008). A escrita de si dentro do processo inicial da docência em EJA, como em um tear que vai urdindo o artesanato, permitiu a percepção do potencial da escrita como processo autorreflexivo e de conhecimento no âmbito das individualidades e coletividade dentro do percurso de formação (JOSSO, 2004, 2010b), permitindo inclusive, tecer identidade docente (MARCELO GARCIA, 2010) em EJA. Além disso, possibilitou reflexões sobre as ações das professorandas antes e depois da inserção nos espaços de estágio em EJA, ampliando a possibilidade de investimento na formação em futuro próximo.

A pesquisa contribuiu para ampliar o foco na formação inicial docente em EJA independentemente do nível de ensino por conta da positiva contribuição do uso das histórias de vida no contexto das biografias educativas - a partir do sujeito aprendente - com entrelace da pesquisa e da formação na melhoria dos processos de aprender e ensinar a gestão da docência para EJA.

Para Josso (2010a) e Souza (2008), o uso dos diários de campo e de aula foi imprescindível para o processo de formação porque registraram percepções, sentimentos, relatos de acontecimentos gerais e particulares como formação e prática didático-pedagógica, inclusive emergindo questões sobre reflexão teórico-metodológica e empírica das aulas e da prática.

O foco na formação envolvendo as especificidades dos sujeitos da EJA naquela realidade, inclusive fazendo o uso das biografias educativas em suas práticas de aula nos estágios, foi um item diferenciador nessa formação. Esta pode ser uma pista para o fortalecimento das políticas de formação e de conhecimento na docência em EJA, tendo em vista que a formação de professores para esta modalidade de ensino ainda possui ações bastante diversificadas e dispersas em todo país, emperrando a identidade docente para EJA.

Essas experiências de formação foram formadoras, no sentido que lhes dá Josso (2010b), porque houve aprendizagem das professorandas ao se relacionarem com os saberes iniciais para a docência, conhecerem a realidade dos sujeitos da EJA, entrelaçarem práticas docentes em relação à EJA e metodologia da perspectiva do campo (auto)biográfico para o primeiro segmento do Ensino Fundamental, trazendo impactos positivos com relação às investigações paralelas junto 
ao campo da formação docente em EJA. As professorandas viveram experiências que impactaram sua formação e vida, como pudemos ver nos depoimentos.

Quanto a nós, professoras pesquisadoras, nos fez perceber que as aulas têm muito mais significado e pertinência a partir dos usos das biografias educativas como caminho de ensino e aprendizagem mútuos. Novos fios foram trazendo os tons das cores para um futuro no qual pretendemos aprofundar essa metodologia na ampliação de nossa docência em EJA e pesquisa. Essa experiência impactou e transformou nossa identidade pessoal e profissional à medida que fomos conectadas as outras subjetividades e identidades a partir de nossos alunos, aproximando-nos. Nesse constante tornar-se, em meio às lutas e tensões do cotidiano, vamos conhecendo na ação, refletindo-a frente ao fazer cotidiano junto com nossos alunos que fortalecem nosso autodesenvolvimento profissional embasado na prática reflexiva e, com isso, vamos ampliando a compreensão e intervenção quando nos aprofundamos nas investigações no campo da formação docente em EJA.

Assim, vamos deixando nossa marca no engenho da seda da docência em EJA tecendo a formação na incessante curiosidade e criatividade em encontrar novas tonalidades, testar misturas e criar outras cores no tear educativo em EJA.

\section{REFERÊNCIAS}

ARROYO, M. G. Que outros sujeitos. Que outras pedagogias? In: ARROYO, M. G. (Org.). Outros sujeitos, outras pedagogias. 2. ed. Petrópolis: Vozes, 2014. p. 37-47.

BRAGANÇA, I. F. S. História de vida e formação de professores: diálogos entre Brasil e Portugal. Rio de Janeiro: UERJ, 2012.

BRAGANÇA, I. F. S. História de vida e formação de professores/as: um olhar dirigido à literatura educacional. In: SOUZA, E. C.; MIGNOT, A. C. V. (Org.). História de vida e formação de professores. Rio de Janeiro: Quartet: Faperj, 2008. p. 65-88.

BRASIL. Conferência Nacional de Educação Básica (CONEB). Brasília, DF: MEC, 2008.

DOMINICÉ, P. L' histoire de vie comme processus de formation. Paris: L'Hamarttan, 1990.

FERRAROTTI, F. História e história de vida: o método biográfico nas Ciências Sociais. Natal: UFRN, 2014.

Educação \& Formação, Fortaleza, v. 3, n. 8, p. 118-137, maio/ago. 2018

DOI: http://dx.doi.org/

http://seer.uece.br/redufor 
FIDALGO, F.; MACHADO, L. (Ed.). Dicionário da educação profissional. Belo Horizonte: UFMG: NETE, 2000.

FONTOURA, H. A. Analisando dados qualitativos através da tematização. In: FONTOURA, H. A. (Org.). Formação de professores e diversidades culturais: múltiplos olhares em pesquisa. Niterói: Intertexto, 2011b. p. 61-82.

FREIRE, P. Pedagogia da autonomia. Rio de Janeiro: Paz e Terra, 2000.

FREIRE, P. Pedagogia do oprimido. Rio de Janeiro: Paz e Terra, 1987.

JOSSO, M.-C. As experiências ao longo das quais se formam identidades e subjetividades. In: JOSSO, M.-C. (Org.). Experiência de vida e formação. 2. ed. São Paulo: Paulus, 2010a. p. 27-43.

JOSSO, M.-C. Caminhar para si. Porto Alegre: PUCRS, 2010b.

JOSSO, M.-C. Cheminer vers soi. Lausanne: L'Age D'Homme, 1991.

JOSSO, M.-C. Experiência de vida e formação. São Paulo: Cortez, 2004.

LARROSA, J. Dar a ler... talvez. In: LARROSA, J. Linguagem e educação depois de Babel. Belo Horizonte: Autêntica, 2004. p. 15-32.

LARROSA, J. Notas sobre a experiência e o saber de experiência. Revista Brasileira de Educação, Rio de Janeiro, n. 19, p. 20-28, 2002.

MARCELO GARCIA, C. O professor iniciante, a prática pedagógica e o sentido da experiência. Revista Brasileira de Pesquisa sobre Formação de Professores, Belo Horizonte, v. 2, n. 3, p. 11-49, 2010.

NÓVOA, A. Os professores: um "novo" objeto da investigação educacional? In: NÓVOA, A. (Org.). Vida de professores 4. 2. ed. Porto: Porto, 1992. p. 14-17.

NÓVOA, A. Para uma formação de professores construída dentro da profissão. Revista de Educación, Madrid, p. 1-10, 2009.

PASSEGGI, M. C.; CUNHA, L. M. Narrativas autobiográficas: a imersão no processo de autoria. In: VICENTINI, P.; SOUZA, E.; PASSEGGI, M. C. (Org.). Pesquisa (auto)biográfica: questões de ensino e formação. Curitiba: CRV, 2013. p. 43-57.

PINEAU, G.; MICHELE, M. Produire as vie: autoformation et autobiographie. Montreal: Edilig, 1983.

SOARES, L. J. G. Analisando pesquisas de Educação de Jovens e Adultos. In: SOARES, L. (Org.). Educação de Jovens e Adultos: o que revelam as pesquisas. Belo Horizonte: Autêntica, 2011. p. 15-22. 
SOARES, L. J. G. Avanços e desafios na formação do educador de jovens e adultos. In: MACHADO, M. M. (Org.). Formação de educadores de jovens e adultos. Brasília, DF: Secad/MEC: Unesco, 2008. p. 57-72.

SOARES, L. J. G. Educação de Jovens e Adultos. Rio de Janeiro: DP\&A, 2002.

SOARES, L. J. G. Formação de educadores de jovens e adultos. Brasília, DF: Secad/MEC: Unesco, 2006.

SOARES, L. J. G.; SOARES, R. C. S. O reconhecimento das especificidades da Educação de Jovens e Adultos: constituição e organização de propostas de EJA. Dossiê EJA II, v. 22, n. 66, p. 1-25, 2014.

SOUZA, E. C. Histórias de vida, escritas de si e abordagem experiencial. In: SOUZA, E. C.; MIGNOT, A. C. V. (Org.). Histórias de vida e formação de professores. Rio de Janeiro: Quartet: Faperj, 2008. p. 89-98.

Recebido em 11 de fevereiro de 2016. Aceito em 16 de julho de 2018. 